Theories \& Applications, the International Edition

Printed Version: (ISSN 2090-5262)

Online Version: (ISSN 2090-5270)

November 2012, Volume 2, No. 3 Pages (92 - 103)

\title{
The Requirements of the Quality of Sports Facilities in Recreational Sports Organizations in Almadina Almonawara
}

\author{
Abdulrahman Arif Abdulgawad*, Yousef Mohamed Yousef**, Shojaa Bin Hassan Hadad***
}

\section{Introduction:}

$\mathrm{T}$ he Success of ISO management applications at any institutions for sport activities depends on the degree of the officersin- charge consciousness of the philosophy of the total quality management deemed as one of the modern philosophies management.

Quality management is a general plan that implies all the hierarchal levels of management and calls for the applications of quality standards, and stresses the joint-responsibility of the staff working at this institutions.

Quality management aims mainly at achieving excellence at the performance of the sport institutions via consumers needs' satisfaction.

Total Quality management assumes different forms so as to be compatible with physical and sporting required areas. As an approach it does its best within the boundaries of available potentials to realized the aspired sporting goals.

The application of total management is related to different element and areas. Its elements can be operated in an integrative manner if we make a balance between private concerned with operators at the sport institutions on the one hand and the public interests on the other hand.

This can be done if we pay attention to the interacting of social forces, economic factors, political variables as well as code of ethics that acknowledges.

Employee rights, duties via governing rules and executive legislations (5). With in this context, Elshaffei (2003) mentioned that the applications of quality management seeks the fulfillment of

* Assistant Professor, Taiba University, Saudi Arabia

** Assistant Professor, Taiba University, Saudi Arabia.

*** Assistant Professor, Taiba University, Saudi Arabia. the consumer is needs desires and expectations at the institutions of sport and physical activities whether this consumer is a sport performer, administrator, or a coach.

One Justification to apply total quality management at sport institutions is its relevance as a technique to evaluate comprehensibly its mission covering all fields and activities. Application of that technique in Arab countries needs an endless efforts not only to assure its competence but also to attain international levels as valid criteria.(16)

The object of this study is to investigate to what extent the pre-requisites of implementing the comprehensive quality management are available as well as the suitness of administrative at sport and recreational institutions at el madina atmosphere to activate such philosophy. This entails fulfilling several objectives identifying the staff working awareness at different managerial levels training context and beneficiaries about the philosophy total quality management and their appreciation of sport product for members of sport and recreational institutions at el madina el menswear - KSA.

The importance of that research is afford a lot of capacities for members working at these sport institutions based on their felt-needs to empower them to apply the principles of quality management as a doctrine develop the performance of their institutions. It sets a real vision for continuous. Training to acquire skills necessary for the institutions man power to implement the concept of quality management and mechanisms. Situating sport and recreational institutions at the centre of the centre of debate on managerial reforms makes this study a timely and significant addition to the literature of the total quality management. It 
is an attempt to delve into the status que of the sport and recreational institutions at el-madina el-menawara as well as a tool to evaluate the total quality of these institutions.

\section{Research Objectives:}

1. Identifying the potential of achieving high quality management of sport and recreational institutions at el-madina el-menawara based on the stand point of customer service beneficiaries.

2. Identifying the availability of high quality management at the sport and recreational institutions based on its staff working members . The research arises several questions about the availability of high quality management discipline at the sport and recreational institutions in el-madina el-menawara city from two contrasting views of its staff working members and the beneficiaries at these institutions.

\section{Research Identifiers:}

Sport and recreational institutions is a collective association related to sport field as a distinctive career or industry, its objective is constructed around the nature of activities it performs, the interacting relationship between these activities and other societal association.

\section{Research Methodology:}

The research team depends on descriptive survey approach partly because it enables us to screen problems to identify issues at stake, points of strength and weakness. As a qualitative approach, it elaborates on the identification of the status quo of the phenomena, its related aspects and roots, as well as suggesting solutions.

\section{Study limitations:}

The study includes all specific sport institution that do not go beyond $200 \mathrm{~m} 2$, so any institutions that is below $200 \mathrm{~m} 2$ is excluded.

\section{The study sample:}

the respondent's amounts to 180 of the beneficiaries, 169 of the questionnaire are valid whereas the sample of the staff working members at the sport institutions at almandine is 13 . only 23 of their questionnaire are viewed as valid.

\section{The research tools:}

the questionnaire design is based on reading previous literature related to the study areas as well as theoretical references which have bearings on the study area. Two questionnaire were designed: one is administered to the customers who benefit from sport institutions whereas the other is applied to the staff members working at these institutions. The breakdown of items at the two questionnaire run as follow:

first customer sport service opinion has two branches: the respondents personal data and a seven-dimension instrument that comprises 85 items (see table no.1) that stand for quality management per-requisites. Second the staff member working opinion has two branches: their personal data and an eight dimensions that comprises 112 statements (see table no.2). 
Table (1)

Dimension and items

\begin{tabular}{|c|c|c|c|c|c|}
\hline $\mathrm{N}$ & \multicolumn{2}{|l|}{ staff member } & $\mathrm{N}$ & \multicolumn{2}{|l|}{ customer opinion } \\
\hline 1 & Administration awareness of the idea of quality & 17 & 1 & $\begin{array}{l}\text { Healthy conditions for training inside the } \\
\text { institutions }\end{array}$ & 7 \\
\hline 2 & $\begin{array}{l}\text { Selection and appointing manpower at the } \\
\text { institutions }\end{array}$ & 12 & 2 & Pricing of services (subscription) & 6 \\
\hline 3 & Orientation toward the client and service pricing & 15 & 3 & Potentials and information system & 25 \\
\hline 4 & Active management of human resource & 13 & 4 & Orientation toward the client & 9 \\
\hline 5 & Potentials and information system & 23 & 5 & $\begin{array}{l}\text { The awareness of administration about the idea of } \\
\text { quality }\end{array}$ & 10 \\
\hline 6 & Continuous improvement of service quality & 11 & 6 & Staff members working at the institutions & 14 \\
\hline 7 & Training and rehabilitation & 15 & 7 & The acting administration of human resources & 14 \\
\hline 8 & $\begin{array}{l}\text { The Healthy conditions for training inside the } \\
\text { institutions }\end{array}$ & 7 & & & \\
\hline & Total & 112 & & Total & 85 \\
\hline
\end{tabular}

Pilot Study:

An exploratory is conducted to verily the validity and reliability of the measurement as follow:

Validity: content validity was examined via a number of arbitrators who enjoy a good experience in the field of recreation, management, recreational services, and quality management .Their endorsement of the questionnaire statement reflects the content validity of the measurement.
Reliability: of the measurement is proved via split-half method of Sperman Brown and Gutmman general equation. Coefficient of reliability for the two questionnaires of exploratory samples is calculated.

Based on data in table (2), both questionnaires enjoy a high degree of reliability as a measure of service quality management at the sport and recreational institutions at el-madina elmenawara city.

Table (2)

Coefficient of reliability

\begin{tabular}{|c|c|c|c|}
\hline \multirow{2}{*}{ questionnaire } & \multicolumn{2}{|c|}{ Sperman Brown } & Gutmman \\
\cline { 2 - 4 } & Correlation & reliability & reliability \\
\hline $\begin{array}{c}\text { 1. Customers } \\
\text { questionnaire }\end{array}$ & 50.843 & 0.902 & 0.884 \\
\hline $\begin{array}{c}\text { 2. staff members } \\
\text { questionnaire }\end{array}$ & 50.815 & 0.891 & 0.867 \\
\hline
\end{tabular}

Significant at $(P \leq 0.05)$

Field study: A pre-test for the two questionnaires was administered at two small groups of all customers and staff members of the institutions to select proper statements.

This was operated on the first semester of 2011. Date were compiled and organized, and finally analyzed.

\section{Statistical analysis:}

Data are delalt using SPSS 6 program via the following Statistical treatment:
1. sperman simple correlation coefficient

2. Brown sperman reliability coefficient

3. Gutmman general equation for reliability

4. Percentages

5. Chi-square ( $\mathrm{x} 2)$

\section{The scores are estimated as follows:}

$\mathrm{No}=0$. yes $1=1$, yes $2=2, \quad$ yes $3=3$, yes $4=4$, yes $5=5$.

6- weighted scores run as follows: 
weighted score for any statement $=$ no. of negatives response $x$

no. of responses of yes $1 \times 1+$ no.

of response of yes $2 \times 2+$ no. of responses

of yes yes $3 \times 3+$ no. of responses

of yes yes $4 \times 4+$ no. of responses

of yes yes $5 \times 5+$ no.

7- weighted percentages:

the weighted degree of statement $=$

weighted percentages of the statement $\times 100$

number of sample (n)

\section{Results \& Discussion:}

Presentation of results elated the stand points of customer dealing with sport and recreation institutions:

1. As to benefiting the customer from the first dimension that deal with the availability of health care at sport clubs, the statement with the highest weighted percentage score (0.575) health care condition are Taken into consideration innate the institution whereas the second statement with the lowest weighted percentage score $(0.50)$, there is a specialized doctor in case of emergency. The first statement is statistically insignificant to favor The response "yes" at five degree. This in due back to the ambiguity of health condition concept on the part sport service users at these insinuations. The second statement, the least agreed upon item, was a logic response in that there is a difficulty in appointing specialized doctor in each club as it represents a load on the club customer. Overall healthy condition necessary for training at the institution is available at percentage of $46.7 \%$ from the customer point of views. It is statistically significant to favor response yes No.1. The research team justified its lowest score of acknowledgment by customer in that healthy aspects at the clubs are not satisfactorily available

2. As to the customer stances toward the second dimension "pricing services" "there are offers item: to subscribe for long terms with specific reduction at the subscription value at weighted percentage of 55.9.10 in favor of yes No.5 response whereas the leant agreed upon statement is there is a variety of subscription to suit customer at weighted percentage of $46.5 \%$. both statement are statistically significant in favor of yes No.5 response. The research team justifies the first statement on the basis that customer low priced, long term subscription is attractive way to afford high capital liquidity for the club to develop the potentials of the clubs whereas the second sentence is justified as the majority of sport institution confine its services to specific social class in accordance with its capital, potentials and installation regardless of other social classes. When we reconsider the items of pricing services dimensions at the sport institution, it is clear that it unsatisfactory for customers in that the percentage of their satisfaction totaled $50.5 \%$ which is considerably low. This refers to the need of such institution to reconsider its service pricing policy to satisfy the needs of customers at sport institution.

3. As to the item of the third dimensions namely, the utilization of sport potential of the institution, the study took further step in pursuing three questions: $a$. computer service $b$. material potential c. the utility of the institution. As to computer services the statement that enjoy the highest agreement by customer, there is an integrated system of information about the customer i.e. member at weighted percentage $45.6 \%$ whereas the least agreed upon statement is, there is an electronic web for correspondence to communicate with member at weighted percentage of $27.5 \%$. The two statement are statistically significant, but, one to favor the response yes at one agree whereas the second to favor the response "No". The low endorsement of the first statement indicates customer insufficient satisfaction with information system at their sport institutions. However, no response on the second statement medicate the absence of communication network i.e. telephone and internet between the customer and their institution, an idea that reduce the interaction between customer and sport institution. Overall, the weighted percentage of customer satisfaction with computer services at their institution amount to $37.6 \%$ whose significance emphasize the reality of response with 'No' 
- As to the affluence of material potential, the highest agreed upon statement is, the available material potential help to achieve the goals of the institution with weighted percentage of $39.5 \%$ whereas the least agreed upon statement is, Developing and modernizing equipment and appliance in available periodically. With weighted percentage of $29.9 \% /$ the two statement are statistically significant but, one in favour of yes. degree often suggest the absence of replacing and modernizing the equipment and appliance of the institution in that it is ready that the institution modernizes its fixtures and tools . It in an expensive process, the idea that affects negatively on customer' satisfactions with services offered by the sport institution. In addition, the weighted percentage for customer' satisfaction with material potential i.e. equipment at the institution amount to $34.5 \%$, which is statistically in favour of the response 'No'.

- One step up the ladders, the highest statement of measuring customer' satisfaction about the utilities at the sport institution is hot water is available inside W.C with weighted percentage of $46.3 \%$ whereas the least agreed upon statement is ' there is a place special for selling sport product need by the customer' with weighted percentage of $23.4 \%$. Both statements are statistically significant, but, the first tends to say 'yes' with one degree whereas the second is in favour of 'No'. To sum up, the weighted percentage of customer satisfaction with the utility of their sport institution amounts to to $35.9 \%$ which is significant in favour of saying 'No'. The average of responses to measure customer satisfaction about the utilities as a whole is $36 \%$.. It is extremely low and highlights the customers, dissatisfaction with the current utilities.This runs in parallel with the findings provided by rehab Amir (2004/9). She proved the inadequacy of accessible potential necessary to realize the objectives of sport institution in general.

4. As to the result of the forth dimension namely Orientation towards the customer at the sport institution, it appears that the statement with the highest score of customer endorsement is customer satisfaction is the main objectives
$33.7 \%$ both statement 'management at the imitation perform pilot- percentage of $28.3 \%$ both statements enjoy statistical significance, but, one in favour of emphasizing No which indicate that the sport institution seeks only profits not customer satisfaction. In addition, the statistical significance of the second statement reveal that customer disbelief of the institution having a future vision plan to develop the routine at the recreational sport clubs. Tables (4) indicates that customer satisfaction with the dimension of orientation of intuition toward them is unsatisfactory.

as it amounts $31.1 \%$ so, it is deemed necessary that such institution must be more customer oriented via developing into policy and treatment with customer as well as increasing the offered service.

5. Table 5 refers to customers, satisfaction with the club administration, awareness of quality management concept. The highest statement agreed upon is" the staff member working at the sport institution regard the realization of customers, needs and desire is in essential part of their job" with weighted percent .

- Age of $33.4 \%$ whereas the least agreed upon statement is scientific technique are used to improve the work "with weighted percentage of $28.3 \%$. The interest aroused was that the two statements are significant in emphasizing 'NO response. This fit two facts: The customer does not feel that the staff member are not optimizing the customer interest but they are after other interests .2. There is no scientific approach to operate sport institution but it depends on the previous experience of the staff .

- There is no updating for staff member's knowledge generally speaking. Tales (5) indicates. That customer satisfaction is low amount to $30.8 \%$ which is statistically sigh faction to emphasize the idea 'No' more specifically, results stress that the sport institution must use every possible scientific means to develop the concept of quality management. Comparatively, this runs parallel to kishtha (2006) (17) when he found a real deficiency of the staff members knowledge as to quality management concept at sport institutions. 
6. It is perhaps invidious to single out customer' satisfaction with the staff member at sport institutions as its percentage amounts to $43.5 \%$ which is statistically significant in favour of yes degree 1. It is moderately low, that reflects customer' dissatisfaction with services offered by the staff members. However, the highest statement agreed upon by customers is 'staff member enjoy skills of communication and support of human relationship at weighted percentage of $51.4 \%$ whereas the least agreed upon statement is the number of the staff member is good proportion.

Ten with the number of the staff member customer'. With weighted percentage $32.9 \%$. Both statements are statistically significant, but, one in favour of' yes degree 5. This indicates the staff members success in establishing

- Human relation with customers and a good indicators ors of institution's success in selecting personnel. The second statement in fallow of 'No' the fact that often takeS place to cut down operation. This is a wrong idea in that the existence of suitable number of manpower that is proportional to the number of customer affects the number of participating customer as well as the revenue

7. The dimension of effective management of human element at the sport reflects customers' satisfaction about personnel. The highest agreed upon statement is 'there is a clear plan for the institution on its personnel needs' with weighted percentage of $45.2 \%$ whereas the least agreed upon statement is 'there are training programs to develop and improve the skills of the personnel. Both are statistically significant in favor of assuring the idea of 'No'. This fits two facts:

- Customers believe that health managerial staff has no plans for future recruiting of manpower qualitatively or quantitatively.

- The sport institutions need more effective management of human resources and a clear plan for personnel needs assessment and developing their skills. This emphasizes Rehab Amin findings (20) However, the percentage of customer who are satisfied with the dimension of the effective management of human element at the institution". Amount to $31.6 \%$.
It is statistically significant and reflects law customers satisfaction

\section{Results presentation of personnel Questionnaire:}

1. Presentation of personnel stand points on
the first dimension degree of institution
administration awareness of quality
management: The highest agreed upon statement is the role of the high level management is to guide and follow up the personnel with weighted percentage of $70.4 \%$ whereas the lowest agreed upon statement id 'careful about technical details' with weighted percentage of $24.3 \%$. Both statements are statistically significant, but the first confirms 'yes' to indicate the pivotal role of high manager level is to guide and follow up workers. This agrees totally to the findings of Ayman Abdou and Rania Morsi (4).

The other statement condemns the sport management institution in that they pay little attention for technical details. However, the research team justifies this behavior as it is expensive and burden on the managerial staff. In general managers' awareness of quality management reaches $54.1 \%$ according to the staff members' stances. It is statistically significant in identifying law awareness of managers of the quality management premises. This confirms results highlighted Omar Nasralla (17) 'that there is a lack of understanding the concept and importance of total quality management in sport activities.

\section{Results discussion of the second dimension on selection and appointing at the institution:} The highest statement agreed upon by the personnel is "Personnel here are punctual about work hours" with weighted percentage $67.8 \%$ whereas the lowest agreed upon statement is "number of personnel is in harmony with their work size" with weighted percentage $20.9 \%$.

Both are statistically significant, but the first is in favor of assuring yes response at five degree. This is natural as view them as punctual. The second confirms the in proportion between personnel assignments and their number at their institution. They view that the management cut down expenses by reducing the manpower at their institution, so, personnel believe that they 
are overburden in return for low salary. In general, the statement of that dimension is satisfactory by $53.6 \%$ of the respondent. It is positively significant in favor of confirming yes response degree five.

\section{Results discussion for the third dimension} on personnel's satisfaction towards customers and pricing of services: The highest statement agreed upon by the institution personnel is 'there are long term offers for subscription at lower prices" with weighted percentage of $65.2 \%$ where the lowest one is 'services offered by the administration meet all customers' needs' with weighted percentage of $20 \%$. The two statements are statistically significant but the first is in favor of conforming yes degree 5". This run parallel with customers' response, this indicates high frequency of such offers. On the other hand, the second statement is significant and confirms "NO" response. It refers to the dissatisfaction of personnel with services offered to the customers overall response concerning persommel's satisfaction towards customers and pricing of services. i.e.: subscription, its weighted percentage amounts to 44.8 and significantly in favor of yes at one degree.

This shows the absence of satisfaction with services offered to the customers and the pricing of subscription.

\section{Results discussion of the fourth dimension:}

The active management of human element at the sport institution: The highest agreed upon statement at that dimension is 'there is a follow up for the new comers personnel during the test period" with weighted percentage $60 \%$ whereas the lowest statement is promotion at our institution is based on competence", with weighted percentage of $14.8 \%$

Both statements are statistically significant but the highest one is in favor of "YES" with one degree, the idea that emphasizes moderately the institution management oversees" its new coming personnel. However, the lowest agreed upon statement reflects feeling of injustice and inequality when it comes to promotion Criteria, the idea affects their performance.

Totally, the percentage of personnel satisfaction with the active management of human elements at sport dimension amounts to 29.8 and statistically significant in favor of confirming "NO". It reflects personnel dissatisfaction with the effective administration of human element in sport institution.

Ayman Abdou and Rania Morsi (2004) (4). It is an indicator that managers do not stick fastidiously to the rules of quality management.

\section{Results discussion of the fifth dimension on the available potential at the institution. This comprises}

A. the use of computer services: The highest statement agreed upon by the personnel of the institution is that there is an integrated information system about the customers at the institution with weighted percentage of $63.5 \%$ whereas the lowest statement carries forwards the idea that there is a special agenda of rules for personnel contraventions and its penalties with weighted percentage of $14.8 \%$. Both are statistically significant, but the highest confirms "yes" response degree 5 whereas the least statement confirm "No" response. The research team view that the owner of sport institution makes full use of computer service in profitable personal areas. However, the second statement of least acceptance indicates the inactivation of reward system when evaluating efforts exerted by personnel. Actually, this lesson personnel motivation for creation and innovation at their performance. Consequently, it affects the quality of work at sport institution.

To sum up the percentage personnel satisfaction with computer services at the institution amounts to $28.8 \%$ which is statistically significant in favor of confirming "NO" response. Based on that, personnel view that there is no proper use of computer services at the sport and recreational institution.

\section{B. Human and material potential of the sport} institution. The percentage of personnel satisfaction with material and human resources amounts to $49.8 \%$. The highest agreed upon statement is that the available material potential can achieve the objectives of the institution "with weighted percentage of $64.3 \%$ whereas the least agreed upon statement is that the distribution of appliance inside the institution is done according to the international training code". With percentage of $19.1 \%$. The two statements are statistically significant but the 
highest confirming the idea of yes at five degrees

Whereas the lowest one is in favor of ' $\mathrm{No}^{\prime}$ response. This is clear evidence that the distribution of equipments and appliances within the boundary of sport institutions differs totally from Arab countries to the developed countries.

This is partly because of in differences in vast areas and great number of appliances allocated to sport clubs at developed countries. The general impression about that item is the dissatisfaction of the personnel with both human and material potentials at these recreational sites.

\section{The status quo of the utilities at the institution:}

The percentage of respondents who are satisfied with the utilities at the institution amounts to $52.5 \%$ which is statistically significant confirming 'Yes' at five degrees. Meanwhile, the statement with the highest percentage of agreement is that affording hot water at the W.C and bathes". With percentage of $61.7 \%$ whereas the least agreed upon statement is that towers, driers, and pampers are available at the institution bath with different sizes" with percentage of $14.8 \%$ confirming the response 'No.' It is logic that recreational sport institution must have hot waters and sanitary health conditions like accessible towels. Absence of these facilities affects passively on the quality of services presented at the sport and recreational institutions. In general, the average response of items at this dimension reaches $43.6 \%$. Comparatively, it is a moderate percentage on light of other dimensions.

There is a clear conviction on the part of the personnel at the sport institutions that the available potentials can achieve satisfactory quality for the customers. This idea runs parallel to findings cited by Rehab Amin study (2004)(20).

6. Results and discussion of the personnel view on sixth dimensions the continuous improvement of service quality at sport and recreational institutions. Based on the data, the statement that has the highest weighted percentage (i.e. $52.2 \%$ ) is that the administration affords written instructions for all types of services offered by the institutions' whereas the statement with the least weighted percentage i.e. $16.5 \%$., personnel are interviewed about the job satisfaction". Both statements are statistically significant but the highest is in favor of confirming 'yes' with five degrees indicates that there are written instruction at the institution which is positive attitude on the part of the institution. However, the lowest statement confirm a sense of detachment between the institution's administration and its personnel in a manner that facilities difficulties interaction, and accountability. In general, personnel satisfaction with the continuous improving of service quality at the institution amounts to $21.5 \%$.

It is statistically significant in favor of stressing 'Negative response towards such improvement of service quality.

7. Results discussion of the seventh dimension about training and rehabilitation at sport and recreational institution: statement with the highest weighted percent age (i.e. 20.9\%) is that there is a periodical and continuous training whereas the statement of the least weighted percentage (i.e. 13\%) is that the administration of our institution uses modern techniques for training and teaching. The two statements are not only statistically significant but they are in favor of stressing 'No' response.

The first statement advocates that the management hold training courses with no indication on the success of such training, the idea that mentioned by Rehab Amin study in (2004) (20). She said that there is a deficiency in educational and training program to improve the personnel performance at sport institution. The second statement reinstates what has been already mentioned in that training courses may not attain their goals because of absence modern training tools and methods.

In general, the statements of that dimension highlight that the percentage of personnel satisfaction with training and rehabilitation amounts to $16.7 \%$ which is extremely low. Statistically, it confirms 'No' response.

8. Results discussion of the eighth dimension dealing with healthy pre-conditions for operating training. 
The statement with the highest weighted percentage $(62.6 \%)$ is that daily cleaning and tidying is taken into consideration and in case of emergency whereas the statement with the least weighted percentage $16.5 \%$ is that in case of emergency there is specialized doctor'. Both are statistically significant but the first is in favor of stressing 'Yes' at five degrees.

At that particular point, the research team view that personnel attempted to highlight their areas of activity.

As to the second statement, it is in favor of confirming 'No' response in that there is no doctor to deal with patients in case of emergency at the institution. The administration wronged that cutting down the expenditure of operation lead to reducing the value of customer's subscription particularly in case of emergency. In general, the dimension statements indicate that percentage of personnel who are satisfied with healthy pre-conditions for training amounts to $53.4 \%$. This percentage is significant and is in favor of stressing yes response at five degrees.

\section{Conclusions:}

Results relevant to customers' satisfaction with sport quality of services at physical and recreational institution in almandine elmanwara city indicate variation in response to different dimensions of the questionnaire. (See table 3 ).

The average of customers' responses to the seven dimensions amounts to $38 \%$ which is moderately low. This indicates that services offered at sport and recreational in el madina el manwara city are weak. This is due to back to the ambiguity of quality management at these institutions simply they have no clear policy to oversee quality criteria or even specific technique to measure customers' reactions towards the services they offer via interviews or customers' suggestions. So, the research team deem it necessary that such institutions must have specific strategy to evaluate customers feed back to improve future service delivery.

In addition, Globalization has challenged the way most people live and entertain. So, sport institution should update its management via borrowing methods to attract more customers. This is clear at the customer's responses towards the idea of low awareness of clubs administrations of quality management in comparison with counterpart at advanced countries $(30.8 \%)$, the clubs' low orientation towards customer service $(31.1 \%)$, and finally the in-efficient use of human element at the clues $(31.6 \%)$. Based on customers' evaluation, the pre-requisites of achieving high quality management at these institutions are weak. 
Table (3)

The degree of satisfaction of both customers and personnel with quality of services at sport, and recreational institutions at el madina el manoura city

\begin{tabular}{|c|c|c|c|c|}
\hline \multicolumn{5}{|c|}{ Customers' Dimensions } \\
\hline No. & Dimension & $\%$ & Dimension & $\%$ \\
\hline 1 & $\begin{array}{l}\text { Health conditions for training } \\
\text { inside the institution }\end{array}$ & 46.7 & $\begin{array}{l}\text { (1) Awareness of the } \\
\text { administration about quality } \\
\text { management }\end{array}$ & 54.1 \\
\hline 2 & Pricing services subscription & 50.5 & $\begin{array}{l}\text { (2) Selection and appointing } \\
\text { personnel at the institution }\end{array}$ & 53.6 \\
\hline 3 & $\begin{array}{l}\text { Orientation towards customers at } \\
\text { the institutions }\end{array}$ & 31.1 & $\begin{array}{l}\text { (3) Orientation towards customers } \\
\text { and service pricing (subscription) }\end{array}$ & 44.8 \\
\hline 4 & Potentials of the institution & 36 & $\begin{array}{l}\text { (4) Personnel satisfaction with the } \\
\text { effective management of human } \\
\text { element }\end{array}$ & 29.8 \\
\hline 5 & $\begin{array}{l}\text { Awareness of the administration at } \\
\text { the institution of quality } \\
\text { management. }\end{array}$ & 30.8 & $\begin{array}{l}\text { (5) Material and human potential } \\
\text { at the institutions }\end{array}$ & 43.6 \\
\hline 6 & The institution personnel & 43.5 & $\begin{array}{l}\text { (6) Continuous improving of } \\
\text { service quality }\end{array}$ & 21.5 \\
\hline \multirow[t]{3}{*}{7} & \multirow[t]{2}{*}{$\begin{array}{l}\text { Effective management of human } \\
\text { element at the institution }\end{array}$} & 31.6 & $\begin{array}{l}\text { (7) Healthy pre-conditions for } \\
\text { training inside the institution }\end{array}$ & 53.4 \\
\hline & & & (8) Training and Rehabilitation & 16.9 \\
\hline & Average & 38 & Average & 40.5 \\
\hline
\end{tabular}

Table (3) highlights the personnel viewpoints on the quality of sport services rendered at their recreational institutional at el madina el manwara city. The average response scale to the eight dimensions amounts to $40.5 \%$ and is viewed as moderately low.

In addition, the respondents reaction towards agreeing on these dimensions has a high variation as to service quality such weak interest in training and rehabilitating the personnel. Only $16.9 \%$ agree on that point whereas $21.5 \%$ of the personnel agree on the idea that there is a continuous updating of service quality. Results affirm the absence of clear vision for quality management at the sport and recreational institutions in el madina elmanwara city. The research team view that the challenges appeared to be daunting as criteria of quality management at these sport institution reaches its minimum level. Self determined knowledge and sharing of content and resources are guides for this institution when evaluating services to customers and personnel. Prospecting charting out of strengths and weakness suggested by customers and personnel facilitate the framework of suggestions to attain quality management at sport and recreational institutions in el madina el manwara city.
Two criteria are suggested to be the yardstick to show the application of quality management: 1 . the institutional capacity and 2. The effectiveness of the services. The first indicate the availability of equipment, tools, convenience to the area of the place, number of trainees, personnel and the healthy convenience whereas the second implies types and levels of services offered by the sport institutions, performance and training levels of personnel, diversity of sport and recreational activities offered at the institution, types of programs offered and how far it satisfies its audiences, types of customers that can be received at these institutions, systems of complaints and suggestions, and the extent of using computer to afford information.

\section{Recommendations:}

1. Utilizing of past international experiences that adapt total quality management at their sport institutions and proved to be fruitful.

2. Concentrating on improving the training of trainer continuously to make proper use of it.

3. Setting up continuous training courses of staff working of the institution on how to implement 
the skills of quality management on the spot and permanent follow up of their performance.

4. Setting up periodic meetings among personnel at different sport institution to brief them on the latest development in the field of quality management as general built - in culture.

5. Establishing scientific criteria when selecting coaches and administration staff based competence and scientific experiences relevant to the concepts of quality management.

6. The administration at sport and recreational institution must enjoy some of flexibility and creativity in its programs, structure, and managerial process to assimilate new variables that affect developing and improving process.

7. Creating strong upward tendency of adapting and disseminating the culture of total quality management in Arab sport institutions.

8. Permanent evaluation of steps for applying total quality management based on a rationale to achieve better quality at sport and recreational institution.

9. Taking decisive measures based on facts to get sustainability as an objective for sport institutions.

\section{References:}

1. Ahmed Sayead Derbas (2001): Total quality management and the possibility of using at Sport Sector. Arab Gulf message. Bibiliatica of Arab Education in Gulf states. Volume 50. Riyad. KSA.

2. Ahmed Sayid Mostafa (2005): Administration of total quality management. Arab society for management. Cairo. ARE.

3. Ali Elsalmee (1995) Total quality management and pre-requisites to qualify for ISO certificate. Dar el Kareab for printing, distribution and publication.

4. Ayman Abdou Mohamed and Rania Morsi Abdo el Abbas Application of total quality management principles and its relation with the professional competencies of physical education teachers in Assiut Governorate.

5. Bahght Attea Rady (A) 2002: Total quality management as an approach to develop the administration sport clubs on the light of recent global changes unpublished $\mathrm{PhD}$ faculty of physical education for boys. Helwan University.

6. Bahgat Atia Radi and Yehia M. ElGeoshe (2006): pre-requisites of applying total quality management an approach to develop physical education sector at the ministry of youth. Journal of Physical education- Elmenofyia Governorate.

7. Effat Allsayed Albar (2003) Total quality management at medical services fields: An applied study on the medical ensurance hospitals. Unpublished M.Sc. Sadat Academy of Administration Sciences.

8. Ekbal Aballa Mohamed (2002) The Role of total quality management in raising performance. Unpublished PhD Sadat Academy for administrative sciences. Cairo.

9. Farid Abd Elfatah Elnagar '2006' Scientific approach to apply total quality management in Arab institution. El Zagazeak University, 2nd edition

10. Gleckner, Dorothy, Schwen: A corelational study of personality characteristic and the Deming Model of Total Quality Management .EDD, The George Washington University1994

11. Ibrahim Bazea (2004) Measuring the central sport quality management at the ministry of education. Unpublished PhD faculty of physical education. Helwan University.

12. Khalid Abd El Aziz (1997) total quality management 2nd edition. Alrhyiad.

13. Magda M. Abd El Hamead: (2000) A proposed framework to apply total quality management approach on the project hospital quality assurance quarantines' unpublished Ph.D. Ain Shams University faculty of commerce.

14. Mohamed Giblak (2002): Evaluating the directors toward the application of total quality management and environment: An empirical study on companies that have an ISO 9000 and ISO 11400 certificate. Unpublished Ph.D. Faculty of Commerce. Ain Shams Univerisity.

15. Mohamed Mady (1995) integrated total quality management. Dar Elmahref. 
16. Mahmoud Dawood Al Rabeey 'Developing erquin sport within the framework of total quality management.

17. Omar Nasralla Kishta (2001) Awareness of total quality management concepts and importance: approach to develop the performance of the Palestinian sport union, Faculty of Physical Education - Al Akssa University Gaza.

18. Paul De Knop, Jo Van Hoecke and Veerle De Bosscher; Quality Management in Sports Clubs. University of Brussels ( Belgium) 2008.

19. Philip Atkinson 1996: Total quality management for cultural change "Translated by Abd El Fatah Alnohmany. Center of professional expertise in management . Cairo.

20. Rehab Ali Amin Oman (2004) study on the obstacles that confront applying total quality management at swimming pools at sport institutions in Alexandria. Unpublished M.Sc. Faculty of physical education for girls Alexandria University.

21. Rodgers, Colleen, Grove : Teacher perceptions of Total Quality Management practices in Elementary schools .EDD, Arizona state university.1998.

22. Rossi, Evelyn, W . : A case study of Essential Implementation characteristics for A successful Total Quality Management program Determination of organizational change through program effectiveness (Quality ,Interpersonal skills, process skills) .EDD ; widener university. 1997

23. Schwegler, Donald, John: Management practices Employed in selected New York state public school Districty ( public Education Total Quality Management continuous Improvement) .EDD; state University of New York at Atbany 1998

24. Siar Ahmed Abd El Rhaman (2006): Building scale for measuring total quality management at sport institutions in the Kingdom of Bahrain Faculty of Education Physical education Dep.

25. Somaya Moran Abd Elk ream (2002): the role of total quality management in improving service performing commercial transaction at banks. Unpublished Ph.D. Al-Sadat Academy for Administration Studies.

26. Tarek Abdalla Kather: A proposed approach to apply total quality management in the field of iron ore industry. Public work sector. Unpublished Ph.D. Faculty of commerce. Ain Shams university.

27. Tarek Abd Raboo Al laban (2001) Evaluation of service quality offered by w.w.w. of information 'internet' in Egypt. Unpublished M.Sc. Sadat Academy for Administrative Sciences. 